\title{
Questionable Reliability of Malondialdehyde to Measure Oxidative Stress in Sjögren's Syndrome: Preliminary Study
}

\author{
Kyung-Eun Lee ${ }^{1}$, Won Jung ${ }^{1}$, Bong-Jik Suh ${ }^{1}$, Seunghee Cha ${ }^{2}$ \\ 'Department of Oral Medicine, Institute of Oral Bioscience, School of Dentistry, Jeonbuk National University, Jeonju, Korea \\ ${ }^{2}$ Department of Oral and Maxillofacial Diagnostic Sciences, University of Florida College of Dentistry, Gainesville, FL, USA
}

Received November 24, 2020

Revised December 15, 2020

Accepted December 16, 2020
Correspondence to:

Kyung-Eun Lee

Department of Oral Medicine, Institute of

Oral Bioscience, School of Dentistry, Jeonbuk National University, 567 Baekje-daero,

Deokjin-gu, Jeonju 54896, Korea

Tel: +82-63-250-2060

Fax: +82-63-250-2058

E-mail: lke@jbnu.ac.kr

https://orcid.org/0000-0001-8923-1478

This paper was supported by the research funds of Jeonbuk National University

Hospital in 2020. This work was supported by the NIH/NIDCR grant DE025726 (S.C.).
Purpose: To investigate the expression of malondialdehyde (MDA), lipid peroxidation marker for oxidative stress (OS), in autoimmune Sjögren's syndrome (SjS) by utilizing the SjSprone C57BL/6.NOD-Aec1Aec2 (B6DC) mouse and the SjS patient plasma samples.

Methods: The MDA concentrations in the lysates of the submandibular gland, liver, and serum samples from the SjS-prone B6DC mouse model were compared with those from the C57BL/6J as a control. A thiobarbituric acid reactive substance (TBARS) assay kit was used to measure MDA. Plasma samples from five SjS patients and five control subjects were also evaluated.

Results: The MDA concentrations in experimental animals and controls were not significantly different. There were no significant differences between the plasma of SjS patients and of controls.

Conclusions: The expression of MDA was investigated in the organs from the SjS-prone B6DC mouse for the first time and in the plasma samples of SjS patients. No significant differences were observed between SjS and control samples when MDA was the target molecule with the TBARS assay. MDA may not be a reliable marker to measure OS contrary to the published studies involving OS of SjS.

Key Words: C57BL/6.NOD-Aec1Aec2; Malondiadehyde; Oxidative stress; Sjögren's syndrome

\section{INTRODUCTION}

Sjögren's syndrome $(\mathrm{SjS})$ is a systemic autoimmune disorder characterized by lymphocytic infiltration in the salivary and lacrimal glands, resulting in severe dry mouth or eyes [1]. The underlying etiology remains relatively unclear, although genetic, environmental, and/or immunologic factors appear to contribute to the etiology [2].

Numerous induced or spontaneous mouse models that resemble various aspects of $\mathrm{SjS}$ have intensively investigated to identify the underlying pathogenesis of $\mathrm{SjS}$ in humans [3]. In recent years, several mouse strains, including nonobese diabetic (NOD), MRL/lpr, CD25 knockout strains, and
C57BL/6.NOD-Aec1Aec2 (B6DC) have been investigated for the immunopathogenic mechanisms of SjS [3,4]. The B6DC mouse is of a $\mathrm{C} 57 \mathrm{BL} / 6 \mathrm{~J}$ (B6) genetic background carrying two genetic segments derived from the NOD mouse. The SjS-prone B6DC mouse does not develop type I diabetes as it does not contain the NOD-derived diabetogenic locus, $\mathrm{I}^{-\mathrm{A}^{\mathrm{g} 7}}[5,6]$. However, it still demonstrates SjS-like disease phenotype in the B6 genetic background similar to the human SjS disease, such as dry mouth and dry eyes [4]. Thus, the B6DC strain is a useful model to identify candidate genes for SjS-like autoimmune exocrinopathy as it allows the identification of disease-associated genes rather than strain-related genes when compared to B6 [7]. The progress

Copyright (c) 2020 Korean Academy of Orofacial Pain and Oral Medicine. All rights reserved.

(c) This is an open-access article distributed under the terms of the Creative Commons Attribution Non-Commercial License (http://creativecommons.org/licenses/by-nc/4.0/), which permits unrestricted non-commercial use, distribution, and reproduction in any medium, provided the original work is properly cited. 
of SjS-like disease in this model can be divided into 3 phases. In phase 1 (0-8 weeks of age), several genetically predetermined physiological abnormalities in organogenesis occur prior to the initiation of disease manifestations [8]. Phase 2 (8-16 weeks of age) is characterized by leukocyte infiltration into the exocrine glands with a concomitant increase of proinflammatory cytokines. In phase 3 (16 weeks of age and older), this mouse strain shows pronounced secretory dysfunctions of the salivary and lacrimal glands, as the hallmark of SjS [9].

Reactive oxygen species (ROS), produced by various cells, such as phagocytes, lymphocytes, cardiomyocytes, hepatocytes, endothelial cells, fibroblasts, and salivary gland cells [10], have useful function serving roles in cell signaling, cell differentiation, cell immunity, etc., when present in low concentrations. These functions are important in maintaining the body's physiological functions known as redox signaling [11]. However, the high level of ROS is dangerous for living organism as they are detrimental to the major cellular components. When the living organisms stay at oxidative stress (OS) state for a long time, the disease will occur in various systems [12]. ROS is thought to be responsible for oxidatively modified autoantigens in autoimmune diseases such as rheumatoid arthritis, systemic lupus erythematosus, systemic sclerosis, type I diabetes mellitus [13]. SjS, which is an autoimmune disease characterized by inflammatory cell infiltration in the exocrine glands, has also reported to be associated with the increased synthesis of ROS [14-16].

The aim of this study is to identify if the expression of OS in $\mathrm{SjS}$ is upregulated even prior to the initiation of SjS-like disease in our mouse model, thereby setting the stage for the full-blown disease phenotype. Therefore, we investigated the expression of malondiadehyde (MDA), which is one of the commonly measured markers for ROS [17], in the submandibular gland (SMX), liver and serum of the 8-week and16-week-old B6DC mice. In addition, the expression of MDA in the plasma of SjS patients was investigated to evaluate if MDA is differentially expressed in patients with $\mathrm{SjS}$ in comparison with the level of MDA in healthy individuals.

\section{MATERIALS AND METHODS}

\section{Animals}

B6DC and B6 were bred and maintained under specific pathogen-free conditions in the Animal Care Services at the University of Florida. The animals were maintained on a 12 hour light-dark schedule and provided with water and food ad libitum. Both breeding and use of these animals were approved by the University of Florida Institutional Animal Care \& Use Committee.

\section{Mouse Tissue Lysate Preparation}

The B6DC female mice were selected at 8 weeks $(n=4$ per group) and 16 weeks ( $\mathrm{n}=3$ per group) of age and agematched B6 female mice as controls. The mice were euthanized by cervical dislocation after deep anesthetization with isoflurane. The SMX and livers of the mice were freshly excised from individual mice. Approximately 25-30 mg of tissue was weighed and placed into $1.5 \mathrm{~mL}$ centrifuge tubes. Radioimmunoprecipitation assay buffer with protease inhibitors was added to each tube with $10 \mu \mathrm{L}$ of the buffer per mg of tissue. Each tissue was homogenized and sonicated on ice and centrifuged at 1,600×g for 10 minutes at $4^{\circ} \mathrm{C}$. The supernatant was placed in a new tube and stored at $-80^{\circ} \mathrm{C}$ for later assay. Blood from the mice was collected with a pipette and placed into a $1.5 \mathrm{~mL}$ centrifuge tube without an anticoagulant and allowed to clot for $30 \mathrm{~min}-$ utes at $25^{\circ} \mathrm{C}$. It was then centrifuged at 2,000×g for 15 minutes at $4^{\circ} \mathrm{C}$. The serum (upper layer) was transferred to a clean $1.5 \mathrm{~mL}$ tube and stored at $-80^{\circ} \mathrm{C}$ before assaying.

\section{Human Plasma Preparation}

Venous blood samples (20 mL/participant) were collected in glass vacutainer tubes containing ethylenediaminetetraacetic acid (EDTA) from five healthy female controls and five SjS patients. Peripheral blood treated with EDTA anticoagulant was utilized to allow for subsequent isolation of peripheral blood leukocytes. To isolate the plasma fraction, whole blood samples were centrifuged at $4,000 \times \mathrm{g}$ for 10 minutes at $4^{\circ} \mathrm{C}$ and plasma supernatants were collected and stored at $-80^{\circ} \mathrm{C}$. SjS diagnosis was based on Modified European-American criteria [18]. The healthy control median age was 34.6 years (range, 25-44 years), and SjS patient 
median age was 56.8 years (range, 47-67 years). This study was approved by the University of Florida Institutional Review Board (IRB no. 201700998) and a written permission was obtained from all participants in the study by collaborators at the University of Florida Rheumatology \& Clinical Immunology clinic.

\section{Measurement of MDA}

Samples for MDA measurement from tissue supernatant, serum and human plasma were prepared by thiobarbituric acid reactive substance (TBARS) assay kit (Caymanchemical, Ann Arbor, MI, USA) in accordance with the company's protocol. Each sample was assayed in triplicate. However, the serum samples of the mice were assayed only once as the amount of the serum was insufficient for triplicate. The fluorescence signals of MDA were read by a plate reader at excitation wavelength of $530 \mathrm{~nm}$ and emission wavelength of $550 \mathrm{~nm}$. The MDA concentrations were calculated by the company's protocol.

\section{Statistical Analysis}

Measurements from each sample were displayed as the mean \pm standard deviation. Significant differences were tested with Mann-Whitney test and unpaired Student's t-test. The statistical significance level was set at 5\% $(p<0.05)$. The tests were performed using GraphPad Prism 5.0 software (GraphPad Software, Inc., La Jolla, CA, USA).

\section{RESULTS}

To investigate if OS is higher in the SMX of the SjS-prone mouse, the level of MDA was measured by the TBARS assay
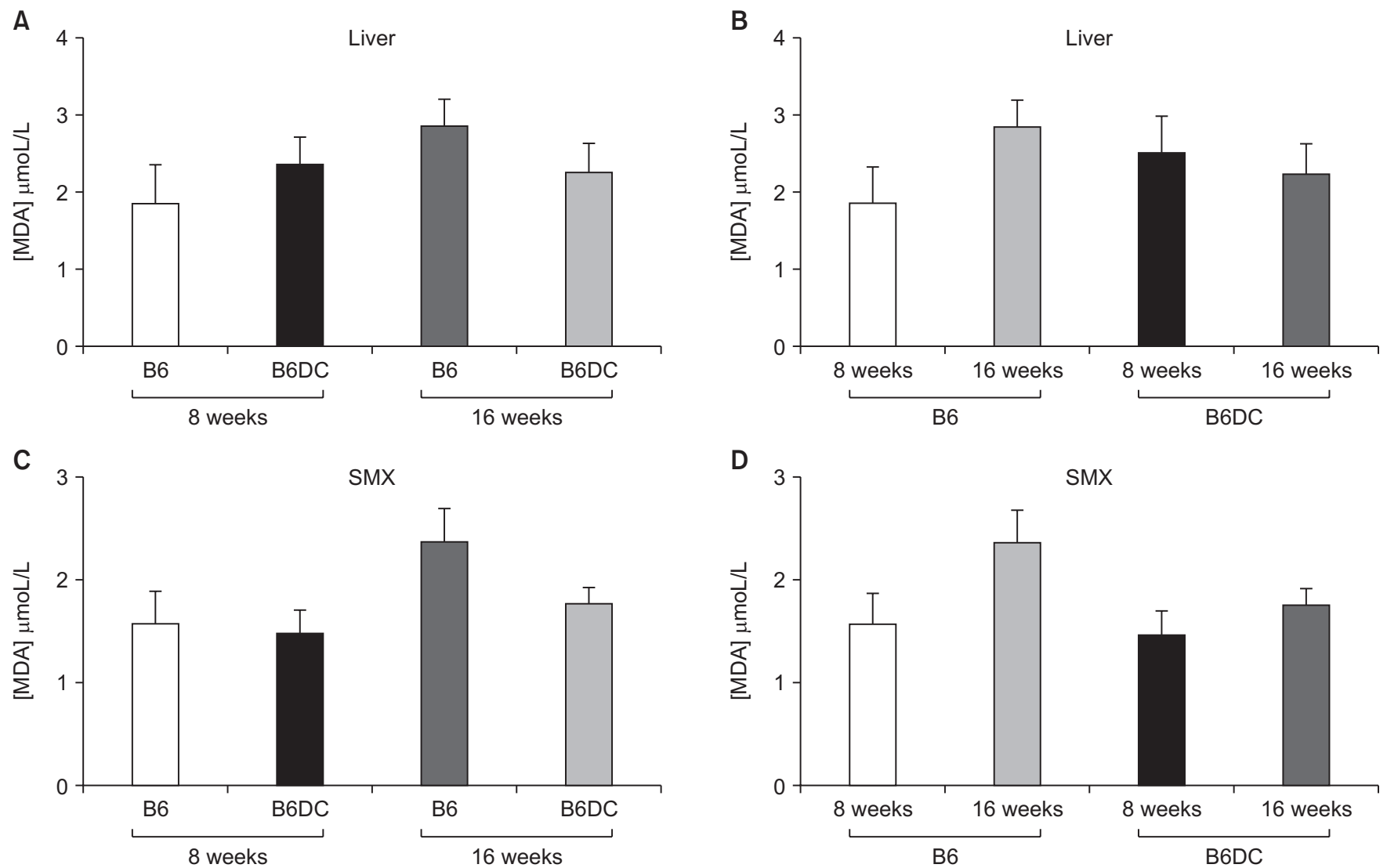

Fig. 1. The concentrations of MDA in the SMX and liver of all groups. The B6 mouse and the B6DC mouse at 8 weeks ( $n=4$ per group) and at 16-weeks ( $n=3$ per group) were utilized for MDA measurements. (A, C) At 8 weeks, the MDA concentrations in the SMX and liver were similar between the groups. At 16 weeks, the MDA levels were lower in the SMX and the liver of B6DC compared to that of B6. (B, D) Interestingly, The MDA concentrations both in the SMX and in the liver increased with age only in the B6 mice. Values are presented as mean \pm standard error of the mean. No statistical difference was observed when unpaired student test analyses were applied. MDA, malondiadehyde; SMX, submandibular gland; B6DC, C57BL/6.NOD-Aec1Aec2; B6, C57BL/6J. 
kit. This kit forms the MDA-thiobarbituric acid (TBA) adduct by the reaction of one molecules of MDA and two molecules of TBA under high temperature $\left(90^{\circ} \mathrm{C}-100^{\circ} \mathrm{C}\right)$ and the MDA-TBA adduct is measured in acidic condition colorimetrically or fluorometrically. A MDA standard was supplied with the kit for the purposes of generating a standard curve. This standard also was utilized as a positive control to validate that MDA was being appropriately detected. Standard curves were linear at each assay and range of $\mathrm{R}^{2}$ was from 0.8829 to 0.9969 .

\section{The MDA Concentration in the SMX of B6DC and B6 Mice}

The MDA concentration in the SMX of the B6 mice was $1.57 \pm 0.63 \mu \mathrm{moL} / \mathrm{L}$ at 8 weeks and $2.37 \pm 0.56 \mu \mathrm{moL} / \mathrm{L}$ at 16 weeks. The MDA concentration in B6DC mice was $1.48 \pm 0.46$ $\mu \mathrm{moL} / \mathrm{L}$ at 8 weeks and $1.77 \pm 0.22 \mu \mathrm{moL} / \mathrm{L}$ at 16 weeks. The MDA concentrations in both 8-week and 16-weekold B6 mice were greater in the B6 than in the B6DC mice. However, the differences were not significant between the groups (Fig. 1A). The MDA concentrations were increased with age in general in both B6 and B6DC groups although a statistically significant increase was not found (Fig. 1B).

\section{The MDA Concentration in the Liver of B6DC and B6 Mice}

The liver was used as a control organ since pathological changes in the liver of B6DC has not been studied or reported to our knowledge. The MDA concentration in the liver of B6 mice was $1.87 \pm 0.95 \mu \mathrm{moL} / \mathrm{L}$ at 8 weeks and $2.86 \pm 0.61$ $\mu \mathrm{moL} / \mathrm{L}$ at 16 weeks. The MDA concentration in B6DC mice was $2.51 \pm 0.99 \mu \mathrm{moL} / \mathrm{L}$ at 8 weeks while the level of MDA was around $2.24 \pm 0.68 \mu \mathrm{moL} / \mathrm{L}$ at 16 weeks. Although the MDA concentration in B6DC was higher than that of $\mathrm{B} 6$ at 8 weeks of age, the difference was not statistically significant (Fig. 1C). There was a trend of increased MDA concentration in $\mathrm{B} 6$ mice as they get older (Fig. 1D).

\section{The MDA Concentration in the Serum of B6DC and B6 Mice}

The MDA concentration in the serum of B6 mice was $1.26 \pm 0.46 \mu \mathrm{moL} / \mathrm{L}$ at 8 weeks and $0.60 \pm 0.11 \mu \mathrm{moL} / \mathrm{L}$ at 16 weeks. The MDA concentration in the serum of the B6DC mice was $1.20 \pm 0.39 \mu \mathrm{moL} / \mathrm{L}$ at 8 weeks and $0.54 \pm 0.23$ $\mu \mathrm{moL} / \mathrm{L}$ at 16 weeks. The statistical analyses were not applied to this comparison because the amount of serum was insufficient to run three independent experiments. The MDA values in the serum of $\mathrm{B} 6$ and $\mathrm{B} 6 \mathrm{DC}$ at each age group showed little difference although the level of MDA was reduced in both groups at 16 weeks of age (Fig. 2A).

\section{The MDA Concentration in the Human Plasma}

To investigate if the MDA level was upregulated in patients with $\mathrm{SjS}$ in comparison with healthy individuals,
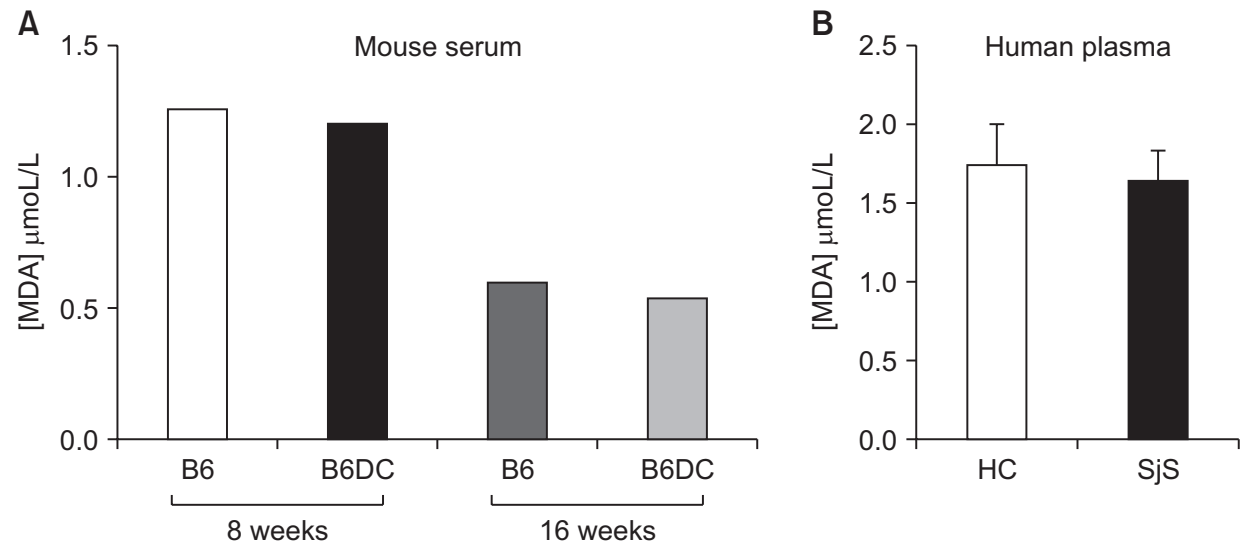

Fig. 2. The concentrations of MDA in the serum of $B 6$ and $B 6 D C$ and in human plasma. (A) The serum of $B 6(n=3$ per group) and $B 6 D C$ ( $n=3$ per group) in each age group show little difference in the levels of MDA. Mice tend to produce less MDA as they get older. (B) The levels of MDA between $\mathrm{HC}(n=5)$ and SjS $(n=5)$ patients are similar. Values are presented as mean \pm standard error of the mean. No statistical significance when unpaired student test was applied. MDA, malondiadehyde; B6, C57BL/6J; B6DC, C57BL/6.NOD-Aec1Aec2; HC, healthy control; SjS, Sjögren's syndrome. 
the plasma samples from healthy subjects and SjS patients were compared for MDA. The MDA concentration of human plasma was $1.75 \pm 0.57 \mu \mathrm{moL} / \mathrm{L}$ in healthy controls and $1.65 \pm 0.43 \mu \mathrm{moL} / \mathrm{L}$ in $\mathrm{SjS}$ patients showing no significant difference between the groups (Fig. 2B).

\section{DISCUSSION}

Only a handful of studies on $\mathrm{OS}$ in $\mathrm{SjS}$ are currently available, which are summarized in Table $1[14,16,19$ 22]. Previous studies have mostly investigated human SjS samples [14,16,19-21] and only one study utilized a mouse model of SjS [22]. All studies have clearly shown increased OS biomarkers in SjS [14,16,19-22]. Ryo et al. [19] showed excess levels of two OS markers, 8-hydroxy-2'-deoxyguanosine and hexanoyl-lysine (HEL), in saliva from $\mathrm{SjS}$ patients suggesting an involvement of OS in SjS pathogenesis. Others reported an increased level of OS in the labial salivary gland of primary SjS patients, measured by markers of DNA, and lipid oxidation [20]. Cejkova et al. [21] showed an increased the level of MDA in the conjunctival epithelium and Wakamatsu et al. [16] found that increased levels of OS utilizing HEL in tear, and HEL and 4-hydroxy2-nonenal (4-HNE) in the conjunctival epithelium of SjS patients.

MDA is one of the secondary products that can be formed during lipid peroxidation, such as propanal, hexanal, and 4-HNE [17]. Since Spiteller et al. [23] had reviewed the involvement of lipid peroxidation in a variety of chronic diseases, MDA emerged as one of the most commonly investigated OS markers [17]. However, the MDA evaluation in SjS was found in only two studies. As mentioned above, Cejkova et al. [21] showed an increased level of MDA in the conjunctival epithelium of SjS patients utilizing immunohistochemistry. When Jiang et al. [22] compared the MDA level in the liver of 8-week-old NOD mice following treatments with their plant mixtures, the authors found that the MDA level of NOD mice was statistically greater than that of controls. In our present study, to our surprise, the MDA concentrations in both B6DC and in SjS patients were not statistically different from the levels of MDA in controls. The levels of MDA from 8 weeks to 16 weeks were increased with age in B6 mice in this study, which was only consistent with the report that the OS level increased in the ICR mice with the natural aging [24]. On the other hand, it was interesting that the MDA in the liver, not to be affected by the disease, was a little higher than that of SMX, although it is not significantly different.

In addition, we investigated the MDA concentration in the frozen SMX and the liver of B6DC and B6 mice (not presented). These were the samples that were stored at different time points for a long period time for other projects.

Table 1. A summary of oxidative stress in SjS in literatures

\begin{tabular}{|c|c|c|c|c|c|}
\hline Subjects & Biological sources & Biomarkers & Methods & Results & References \\
\hline pSjS patients & Human plasma & AOPP, PC & RP-HPLC & $\begin{array}{l}\text { AOPP and PC levels were increased in the } \\
\text { primary SjS patients }\end{array}$ & [14] \\
\hline \multirow[t]{2}{*}{ SjS patients } & Tear & HEL & $\begin{array}{l}\text { Commercially } \\
\text { available ELISA }\end{array}$ & $\begin{array}{l}\text { Tear HEL concentrations correlated significantly } \\
\text { with staining scores }\end{array}$ & [16] \\
\hline & Conjunctival epithelium & HEL, 4-HNE & $\mathrm{IHC}$ & $\begin{array}{l}\text { The numbers of conjunctival cells stained } \\
\text { positively for HEL and } 4 \mathrm{HNE} \text { were significantly } \\
\text { higher in SS patients }\end{array}$ & \\
\hline SjS patients & Human saliva & $\begin{array}{l}\text { 8-OHdG } \\
\text { HEL }\end{array}$ & $\begin{array}{l}\text { ELISA for } 8-O H d G \\
\text { HEL Kit-700 }\end{array}$ & $\begin{array}{l}\text { Increased levels of 8-OHdG and HEL were } \\
\text { found in the saliva of SjS patients }\end{array}$ & [19] \\
\hline SjS patients & Labial biopsy specimens & $\begin{array}{l}\text { 8-OHdG, } \\
\text { 4-HNE }\end{array}$ & $\mathrm{IHC}$ & $\begin{array}{l}\text { Large amounts of } 8-\mathrm{OHdG}, 4-\mathrm{HNE} \text { were } \\
\text { produced in salivary duct cells of SjS patients }\end{array}$ & [20] \\
\hline SjS patients & Conjunctival epithelium & MDA & $\mathrm{IHC}$ & $\begin{array}{l}\text { The expression of MDA was highly pronounced } \\
\text { in dry eye }\end{array}$ & [21] \\
\hline NOD mice & Liver & MDA & Commercial kits & $\begin{array}{l}\text { MDA level in 8-week-old NOD mice was } \\
\text { greater than in control }\end{array}$ & [22] \\
\hline
\end{tabular}

SjS, Sjögren's syndrome; pSjS, primary Sjögren's syndrome; NOD, non-obese diabetic; AOPP, advanced oxidation protein products; PC, protein carbonyl; HEL, hexanoyl-lysine; 4-HNE, 4-hydroxy-2-nonenal; MDA, malondialdehyde; RP-HPLC, reversed phase-high performance liquid chromatography; IHC, immunohistochemistry; 8-OHdG, 8-hydroxy-2'-deoxyguanosine. 
The variations among the measured concentrations were significantly high, which appeared to depend on the duration of the sample storage. This clearly indicates that MDA measurements should be applied to fresh samples rather than frozen samples.

Our study utilizing plasma samples, although it was a small number of samples, also indicated the concentration of MDA was not elevated both in the SjS-prone animal and in SjS patients compared to controls. This result was similar with the reports where the level of MDA in human plasma samples of Alzheimer's disease and in Type I diabetes was not increased $[25,26]$. However, a review study regarding biomarkers of OS showed elevated MDA levels in the human plasma samples of various diseases, such as amyotrophic lateral sclerosis, Parkinson's disease, and hypertension [27].

The TBARS assay, used in this study, is the most commonly used method to determine MDA in biological fluids and is convenient to utilize, in particular, for large sample numbers, as it needs only a plate reader instrument in clinical research [28]. The assay is based on a condensation reaction of two molecules of TBA with one molecule of MDA to form a red-colored, visible light-absorbing and fluorescent derivative. The reaction is carried out in acidic solution and elevated temperature of $0-95^{\circ} \mathrm{C}$ within one hour time course [29]. Our recent search on MDA, because of our current data showing similar responses among samples or minimal differences among our samples with the TBARS assay, has revealed that there is a consensus that the TBARS assay is nonspecific. This has led to a substantial controversy over its use for quantification of MDA from in vivo samples [17]. The numerous commercial easy-to-use kits lack specificity and their significance for clinical research is questionable [27], since TBA may react not only with MDA but also with several other components [30,31]. Moreover, Treatment of biological samples at high temperature in strong acidic conditions for extended incubation time to obtain the condensation product may generate further oxidation of the matrix with obvious overestimation of the results $[28,30]$. The MDA levels in healthy human plasma measured by the TBARS assay were various from $0.41 \mu \mathrm{moL} / \mathrm{L}$ to $4.45 \mu \mathrm{moL} /$ L [32]. Others reported that TBARS levels, as a biomarker of MDA, in plasma and serum samples of psychiatric patients showed high variations according to the TBA analytic method and were different in the same samples with different analytic method [33].

Several techniques to separate free and total MDA from other components, which are more sensitive and selective compared to the classic TBARS assay, have been developed [28]. High performance liquid chromatography with either ultraviolet-visible spectroscopy or fluorescence detection was suggested as a selective and sensitive method and gold standard among various methods for the MDA evaluation in various biological fluids $[27,34,35]$. However, this method requires individual sample processing and its validity as a marker for in vivo OS remains uncertain [30]. Recently, it was suggested that gas chromatography-mass spectrometry (GC-MS) and GC-MS/MS methods was specific, precise and sensitive for the quantitative determination of MDA [36].

In conclusion, we investigated the MDA concentration in the SMX, liver, and the serum of the SjS-prone B6DC mice at 8 and 16 weeks for the first time and in human plasma of SjS patients. Our result indicate that the level of MDA was not altered in our mouse model along with $\mathrm{SjS}$ patient plasma samples compared with controls, conflicting with other studies, when measured with the TBARS assay. Although it is only hypothetical at this point, it is certainly conceivable that MDA measurement alone may not accurately capture the level of OS in those specimens due to the issues of the assay as mentioned earlier, unless it is combined with more sensitive and reliable measurement methods for OS.

\section{CONFLICT OF INTEREST}

No potential conflict of interest relevant to this article was reported.

\section{ORCID}

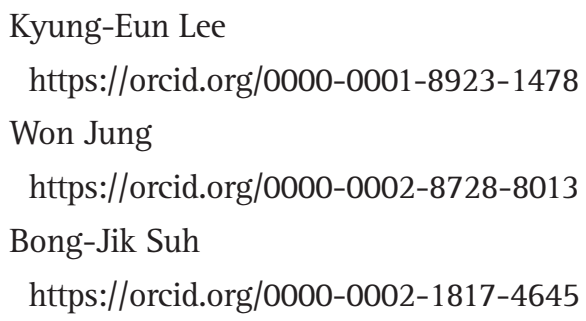




\author{
Seunghee Cha \\ https://orcid.org/0000-0003-3772-1832
}

\section{REFERENCES}

1. Fox RI. Sjögren's syndrome. Lancet 2005;366:321-331.

2. Bayetto K, Logan RM. Sjögren's syndrome: a review of aetiology, pathogenesis, diagnosis and management. Aust Dent J 2010;55 Suppl 1:39-47.

3. Park YS, Gauna AE, Cha S. Mouse models of primary Sjogren's syndrome. Curr Pharm Des 2015;21:2350-2364.

4. Nguyen CQ, Peck AB. Unraveling the pathophysiology of Sjogren syndrome-associated dry eye disease. Ocul Surf 2009;7:11-27.

5. Li X, Golden J, Faustman DL. Faulty major histocompatibility complex class II I-E expression is associated with autoimmunity in diverse strains of mice. Autoantibodies, insulitis, and sialadenitis. Diabetes 1993;42:1166-1172.

6. Wicker LS, Todd JA, Prins JB, Podolin PL, Renjilian RJ, Peterson LB. Resistance alleles at two non-major histocompatibility complex-linked insulin-dependent diabetes loci on chromosome 3, Idd3 and Idd10, protect nonobese diabetic mice from diabetes. J Exp Med 1994;180:1705-1713.

7. Killedar SJ, Eckenrode SE, McIndoe RA, et al. Early pathogenic events associated with Sjögren's syndrome (SjS)-like disease of the NOD mouse using microarray analysis. Lab Invest 2006;86:1243-1260.

8. Robinson CP, Yamamoto H, Peck AB, Humphreys-Beher MG. Genetically programmed development of salivary gland abnormalities in the NOD (nonobese diabetic)-scid mouse in the absence of detectable lymphocytic infiltration: a potential trigger for sialoadenitis of NOD mice. Clin Immunol Immunopathol 1996;79:5059.

9. Robinson CP, Yamachika S, Bounous DI, et al. A novel NODderived murine model of primary Sjögren's syndrome. Arthritis Rheum 1998;41:150-156.

10. Lam GY, Huang J, Brumell JH. The many roles of NOX2 NADPH oxidase-derived ROS in immunity. Semin Immunopathol 2010;32: 415-430.

11. Schieber M, Chandel NS. ROS function in redox signaling and oxidative stress. Curr Biol 2014;24:R453-R462.

12. Mao X, Gu C, Chen D, Yu B, He J. Oxidative stress-induced diseases and tea polyphenols. Oncotarget 2017;8:81649-81661.

13. Kurien BT, Scofield RH. Autoimmunity and oxidatively modified autoantigens. Autoimmun Rev 2008;7:567-573.

14. Norheim KB, Jonsson G, Harboe E, Hanasand M, Gøransson L, Omdal R. Oxidative stress, as measured by protein oxidation, is increased in primary Sjøgren's syndrome. Free Radic Res 2012; 46:141-146.

15. Pagano G, Castello G, Pallardó FV. Sjøgren's syndrome-associated oxidative stress and mitochondrial dysfunction: prospects for chemoprevention trials. Free Radic Res 2013;47:71-73.

16. Wakamatsu TH, Dogru M, Matsumoto Y, et al. Evaluation of lipid oxidative stress status in Sjögren syndrome patients. Invest Oph- thalmol Vis Sci 2013;54:201-210.

17. Ayala A, Muñoz MF, Argüelles S. Lipid peroxidation: production, metabolism, and signaling mechanisms of malondialdehyde and 4-hydroxy-2-nonenal. Oxid Med Cell Longev 2014;2014:360438.

18. Vitali C, Bombardieri S, Jonsson R, et al. Classification criteria for Sjögren's syndrome: a revised version of the European criteria proposed by the American-European Consensus Group. Ann Rheum Dis 2002;61:554-558.

19. Ryo K, Yamada H, Nakagawa Y, et al. Possible involvement of oxidative stress in salivary gland of patients with Sjogren's syndrome. Pathobiology 2006;73:252-260.

20. Kurimoto C, Kawano S, Tsuji G, et al. Thioredoxin may exert a protective effect against tissue damage caused by oxidative stress in salivary glands of patients with Sjögren's syndrome. J Rheumatol 2007;34:2035-2043.

21. Cejková J, Ardan T, Simonová Z, et al. Nitric oxide synthase induction and cytotoxic nitrogen-related oxidant formation in conjunctival epithelium of dry eye (Sjögren's syndrome). Nitric Oxide 2007;17:10-17.

22. Jiang S, Hu L, Ping L, Sun F, Wang X. Glutathione protects against hepatic injury in a murine model of primary Sjögren's syndrome. Bosn J Basic Med Sci 2016;16:227-231.

23. Spiteller G. Linoleic acid peroxidation--the dominant lipid peroxidation process in low density lipoprotein--and its relationship to chronic diseases. Chem Phys Lipids 1998;95:105-162.

24. Yamauchi Y, Matsuno T, Omata K, Satoh T. Relationship between hyposalivation and oxidative stress in aging mice. J Clin Biochem Nutr 2017;61:40-46.

25. McGrath LT, McGleenon BM, Brennan S, McColl D, McILroy S, Passmore AP. Increased oxidative stress in Alzheimer's disease as assessed with 4-hydroxynonenal but not malondialdehyde. QJM 2001;94:485-490.

26. Vessby J, Basu S, Mohsen R, Berne C, Vessby B. Oxidative stress and antioxidant status in type 1 diabetes mellitus. J Intern Med 2002;251:69-76.

27. Frijhoff J, Winyard PG, Zarkovic N, et al. Clinical relevance of biomarkers of oxidative stress. Antioxid Redox Signal 2015;23: 1144-1170.

28. Giera M, Lingeman H, Niessen WM. Recent advancements in the LC- and GC-based analysis of malondialdehyde (MDA): a brief overview. Chromatographia 2012;75:433-440.

29. Tsikas D. Assessment of lipid peroxidation by measuring malondialdehyde (MDA) and relatives in biological samples: analytical and biological challenges. Anal Biochem 2017;524:13-30.

30. Del Rio D, Stewart AJ, Pellegrini N. A review of recent studies on malondialdehyde as toxic molecule and biological marker of oxidative stress. Nutr Metab Cardiovasc Dis 2005;15:316-328.

31. Knight JA, Pieper RK, McClellan L. Specificity of the thiobarbituric acid reaction: its use in studies of lipid peroxidation. Clin Chem 1988;34:2433-2438.

32. Domijan AM, Ralić J, Radić Brkanac S, Rumora L, Žanić-Grubišić T. Quantification of malondialdehyde by HPLC-FL - application to various biological samples. Biomed Chromatogr 2015;29:4146.

33. Khoubnasabjafari M, Ansarin K, Jouyban A. Reliability of malo- 
ndialdehyde as a biomarker of oxidative stress in psychological disorders. Bioimpacts 2015;5:123-127.

34. Breusing N, Grune T, Andrisic L, et al. An inter-laboratory validation of methods of lipid peroxidation measurement in UVAtreated human plasma samples. Free Radic Res 2010;44:12031215.

35. Mateos R, Lecumberri E, Ramos S, Goya L, Bravo L. Determination of malondialdehyde (MDA) by high-performance liquid chromatography in serum and liver as a biomarker for oxidative stress. Application to a rat model for hypercholesterolemia and evaluation of the effect of diets rich in phenolic antioxidants from fruits. J Chromatogr B Analyt Technol Biomed Life Sci 2005;827:76-82.

36. Tsikas D, Rothmann S, Schneider JY, et al. Development, validation and biomedical applications of stable-isotope dilution GCMS and GC-MS/MS techniques for circulating malondialdehyde (MDA) after pentafluorobenzyl bromide derivatization: MDA as a biomarker of oxidative stress and its relation to 15(S)-8-isoprostaglandin F2 $\alpha$ and nitric oxide (NO). J Chromatogr B Analyt Technol Biomed Life Sci 2016;1019:95-111. 